Article

\title{
Rapid Quantitative Detection of Brucella melitensis by a Label-Free Impedance Immunosensor Based on a Gold Nanoparticle-Modified Screen-Printed Carbon Electrode
}

Haiyun Wu ${ }^{1}$, Yueming Zuo ${ }^{1, *}$, Chuanjin $\mathrm{Cui}^{2}$, Wei Yang ${ }^{1}$, Haili Ma ${ }^{3}$ and Xiaowen Wang ${ }^{4}$

1 College of Engineering, Shanxi Agriculture University, Taigu 030801, China;

E-Mails: haiyunwu2013@163.com (H.W.); 200808doudou@sina.cn (W.Y.)

2 College of Electrical Engineering, Hebei United University, Tangshan 063009, China;

E-Mail: cuichuanjin@163.com

3 College of Animal Science and Technology, Shanxi Agriculture University, Taigu 030801, China;

E-Mail: mahaili1718@126.com

4 College of Food Science \& Technology, Shanxi Agriculture University, Taigu 030801, China;

E-Mail: wangx@sxau.edu.cn

* Author to whom correspondence should be addressed; E-Mail: zyueming88@aliyun.com; Tel.: +86-354-6288-400 (ext. 8305).

Received: 20 May 2013; in revised form: 21 June 2013 / Accepted: 21 June 2013 /

Published: 4 July 2013

Abstract: A rapid and simple method for quantitative monitoring of Brucella melitensis using electrochemical impedance spectroscopy (EIS) is reported for the first time. The label-free immunosensors were fabricated by immobilizing Brucella melitensis antibody on the surface of gold nanoparticle-modified screen-printed carbon electrodes (GNP-SPCEs). Cyclic voltammetry (CV) and EIS were used to characterize the Brucella melitensis antigen interaction on the surface of GNP-SPCEs with antibody. A general electronic equivalent model of an electrochemical cell was introduced for interpretation of the impedance components of the system. The results showed that the change in electron-transfer resistance $\left(R_{\mathrm{ct}}\right)$ was significantly different due to the binding of Brucella melitensis cells. A linear relationship between the $R_{\mathrm{ct}}$ variation and logarithmic value of the cell concentration was found from $4 \times 10^{4}$ to $4 \times 10^{6} \mathrm{CFU} / \mathrm{mL}$ in pure culture. The label-free impedance biosensor was able to detect as low as $1 \times 10^{4}$ and $4 \times 10^{5} \mathrm{CFU} / \mathrm{mL}$ of Brucella melitensis in pure culture and milk samples, respectively, in less than $1.5 \mathrm{~h}$. Moreover, a good selectivity versus Escherichia coli O157:H7 and Staphylococcus aureus cells was obtained for our developed immunosensor demonstrating its specificity towards only Brucella melitensis. 
Keywords: quantitative detection; Brucella melitensis; label-free immunosensor; screen-printed carbon electrode; gold nanoparticle

\section{Introduction}

Brucellosis is a worldwide bacterial zoonosis and an important cause for human suffering and economical losses. Brucellosis incidence increased sharply in China since 1995 [1]. About 43,623 cases were reported during 1999-2008 [2]. Brucellosis infections are almost invariably transmitted to people by direct or indirect contact with infected animals or their products. In particular, consumption of unpasteurized milk and dairy products is one of the most important sources of human infection [3].

The etiological agents of brucellosis are various Brucella species, including Brucella abortus, Brucella melitensis, Brucella suis, Brucella neotomae, Brucella ovis, and Brucella canis. In general, Brucella melitensis and Brucella suis are more virulent for humans than Brucella abortus and Brucella canis, although serious complications can occur with any species of Brucella [4]. Currently, Brucella isolation by bacterial culture is still a gold standard method that confirms the existence of the causative agent [5]. Other techniques such as complement fixation test (CFT), serum agglutination test (SAT), Rose Bengal plate test (RBT) and polymerase chain reaction (PCR) are used as supporting methods [3,6,7]. Regrettably, these methods have their limitations, such as labor and time-consuming, requiring complicated sample pretreatment and highly qualified personnel. Moreover, most of these procedures are only adapted for the qualitative or semiquantitative detection for Brucella assays, which do not meet the requirements for the rapid and accurate identification of brucellosis in less time that delays the introduction of efficient remedial measures. As a consequence, the development of rapid, inexpensive, and easy-to-use detection methodologies for Brucella, which can be used by untrained personnel, is vital.

One of the most promising novel techniques is the use of immunosensors. This technology makes use of immunochemicals as molecular recognition elements to construct self-contained devices. Due to high selectivity and sensitivity, immunosensors have been the subject of continued research and development in recent years. Several immunosensors for the detection of Brucella have been reported [5,8,9]. However, most of these sensors are label-dependent that require labeling of bio-molecules to convert the antibody/antigen interaction into detectable optical or electrochemical signals. In contrast label-free immunosensors have attractive advantages with respect to speed, cost, and simplicity of operation [10]. Hence development of label-free biosensors for the detection of Brucella directly in biological samples such as milk, serum, or urine, etc., has attracted the considerable interest.

Label-free detection methodologies for Brucella using surface plasmon resonance (SPR) were reported [11]. The expense of the sensor materials or uncommon measuring instruments would limit out-of-laboratory applications for economic and fast screening. Fortunately, the impedance technique is yet another rapid and inexpensive alternative for label-free biosensors. Electrochemical impedance measurement devices are also suitable for mass fabrication and miniaturization. Traditionally, metal macro-sized metal rods or wires were used as electrodes immersed in a medium to measure the 
electrochemical response [8]. Due to recent developments in biosensor technology, the production of electrochemical transducers using screen-printed carbon electrodes (SPCEs) is well established. Electrochemical immunosensors based on SPCEs challenge the conventional electrochemical biosensors for fabrication, disposability and portability, which make them suitable for working with microvolumes and for decentralized assays (point of care tests) [12]. In particular, the coupling of screen-printed electrodes with metal nanoparticles (such as gold nanoparticles, GNPs) in electrochemical immunosensors has received considerable attention. Since GNPs have large specific surface areas and good bio-compatibility, the use of GNPs as versatile and efficient templates for the immobilization of biomolecules, such as antibodies, target cells or viruses, have been reported by many groups [13-16]. Many recent studies are focused on Escherichia coli and Salmonella detection with electrochemical techniques: impedimetric [17,18], amperometric [14,19] and capacitive [20] measurements, however, few studies were devoted to Brucella melitensis detection.

In this work, we demonstrated a disposable gold nanoparticle-modified screen-printed carbon electrode (GNP-SPCE)-based impedance immunosensor as a new approach for the rapid, simple and quantitative detection of Brucella melitensis. Gold nanoparticles on the electrode will result in large electrode surface area and easy attachment of antibody. The recognition of a monolayer of antibodies immobilised on an electrode by the specific antigens was monitored. Compared to routine immune diagnosis method, this label-free immunosensor is a relatively simple operation and low-cost, which can be used by untrained personnel. This establishes a novel approach for fast detecting Brucella organisms in a point of care real time situation.

\section{Experimental Section}

\subsection{Reagents}

Bovine serum albumin (BSA) and proteinase $\mathrm{K}$ were purchased from Roche Diagnostics $\mathrm{GmbH}$ (Mannheim, Germany). Triton X-100 was obtained from Amresco LLC (Solon, OH, USA). $\mathrm{K}_{4} \mathrm{Fe}(\mathrm{CN})_{6}$ $\mathrm{K}_{3} \mathrm{Fe}(\mathrm{CN})_{6}$, and $\mathrm{KCl}$ were purchased from Solarbio Science \& Technology CO., Ltd. (Beijing, China). Brucellosis positive standard serum $(1,000 \mathrm{IU} / \mathrm{mL})$ was purchased from China Institute of Veterinary Drug Control (Beijing, China). A 1:25 dilution of the serum was prepared in PBS (10 mM, pH 7.4) before use. The buffers and solutions used in this study were prepared as follows: PBS buffer (10 mM, $\mathrm{pH}$ 7.4), blocking buffer (1\% BSA in PBS buffer), and electrolyte solution $\left(2.5 \mathrm{mM} \mathrm{K} \mathrm{Fe}(\mathrm{CN})_{6}, 2.5 \mathrm{mM}\right.$ $\mathrm{K}_{3} \mathrm{Fe}(\mathrm{CN})_{6}$ and $0.1 \mathrm{M} \mathrm{KCl}$ in PBS buffer ). All solutions were prepared with deionized water in a Heal Force water purification system (Smart Series, $18.2 \mathrm{M} \Omega \cdot \mathrm{cm}$, Hong Kong, China).

\subsection{Instruments}

Scanning electron microscopy (SEM) images of electrode surface were obtained using a JEOL-JSM-6490LV scanning electron microscope (JEOL Ltd., Tokyo, Japan). EIS and cyclic voltammetry $(\mathrm{CV})$ measurements were performed with a $\mathrm{CHI} 760 \mathrm{C}$ electrochemical station $(\mathrm{CH}$ Instruments, Shanghai Chenhua, Shanghai, China). All experiments were carried out at room temperature. 
SPCEs functionalized with gold nanoparaticles on ceramic substrate (L $34 \mathrm{~mm} \times \mathrm{W} 10 \mathrm{~mm} \times \mathrm{H} 0.5 \mathrm{~mm}$ ) were purchased from DropSens Inc. (Oviedo, Spain). The disposable electrode consisted of a GNP-carbon working electrode; a carbon counter electrode and a silver reference electrode (Figure 1).

Figure 1. Images of the GNP-SPCE. (a) Photo of the electrode; (b) SEM image of working electrode. The figures originated from DropSens Inc. (Oviedo, Spain).

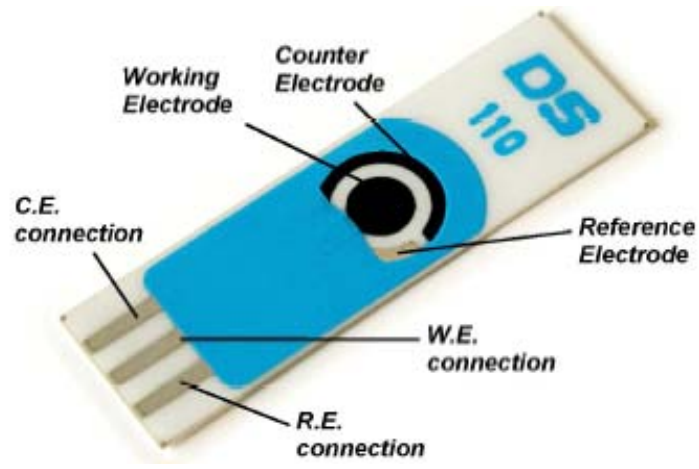

(a)

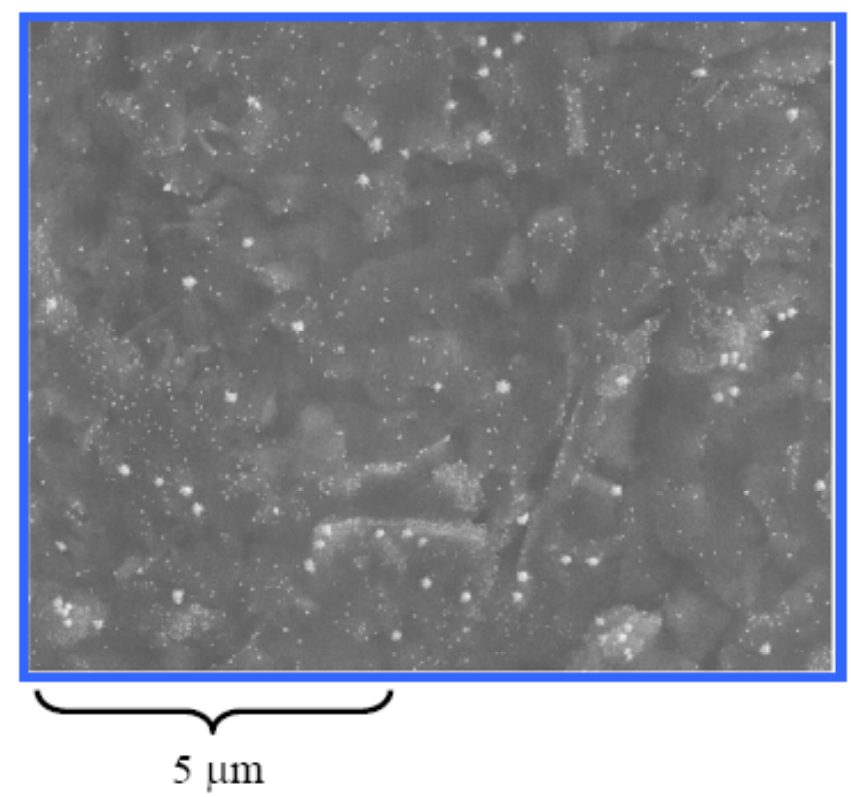

(b)

\subsection{Preparation of Microbial Sample}

Brucella melitensis $\left(4 \times 10^{10}\right.$ colony forming units $\left.(\mathrm{CFU}) / \mathrm{mL}\right)$ was purchased from China Institute of Veterinary Drug Control (Beijing, China). The other bacterial cultures used in this study, including heat-killed Escherichia coli O157:H7 cells $\left(1.15 \times 10^{9} \mathrm{CFU} / \mathrm{mL}\right)$ and Staphylococcus aureus strain (C56024), were obtained from Kirkegaard \& Perry Laboratories, Inc. (Gaithersburg, MD, USA) and the Food Science and Technology College of Shanxi Agricultural University (Taigu, China), respectively. A 10- $\mu \mathrm{L}$ loop of Staphylococcus aureus isolate was grown in Luria-Bertani (LB) liquid culture at $37{ }^{\circ} \mathrm{C}$ for $24 \mathrm{~h}$ to make a stock culture. The stock cultures were serially diluted with PBS buffer. A conventional spread plating method was used for bacterial counts.

A whole pasteurized milk sample was purchased from a local supermarket. In analysis of real-life samples, the milk samples were spiked with different concentrations of Brucella melitensis cells. Next, the samples were treated by the method [14] to eliminate lipids and proteins. Briefly, proteinase $\mathrm{K}$ $(0.25 \mathrm{mg})$ and $50 \mu \mathrm{L}$ of $0.1 \%$ Triton $\mathrm{X}-100$ were added to $100 \mu \mathrm{L}$ samples of milk, and then incubated at $37{ }^{\circ} \mathrm{C}$ for $30 \mathrm{~min}$. After incubation, $900 \mu \mathrm{L}$ of $150 \mathrm{mM} \mathrm{NaCl}$ was added to the samples and the mixture was centrifuged at $12,000 \times \mathrm{g}$ for $10 \mathrm{~min}$. The lipids (top layer) and digested proteins of the milk were drawn off with a micropipette and the bacteria-containing pellets were collected. Finally, the pellets were resuspended in $100 \mu \mathrm{L}$ of $150 \mathrm{mM} \mathrm{NaCl}$ and used for detection of bacteria. 


\subsection{Fabrication of the Immunosensors}

Each working electrode of the GNP-SPCE was incubated with $15 \mu \mathrm{L}$ dilute brucellosis positive standard serum for $30 \mathrm{~min}$ at $37^{\circ} \mathrm{C}$. The GNP-SPCE was then slowly placed in PBS buffer for $30 \mathrm{~s}$, allowing the diffusion of unbound antibodies away from the electrode surface. After this, the GNP-SPCE was rinsed with deionized water two times and blew away residual drops with a stream of nitrogen. This was then followed by blocked each working electrode of the GNP-SPCE with $15 \mu \mathrm{L}$ of blocking buffer for $60 \mathrm{~min}$ at $37^{\circ} \mathrm{C}$. Finally, they were slowly immersed in PBS buffer for $30 \mathrm{~s}$ and washed twice with deionized water. Then they were blew again with a stream of nitrogen and stored at room temperature in a clean box before use.

\subsection{Measurement Procedure}

A volume of $15 \mu \mathrm{L}$ sample for test was applied to the immunosensor on the working electrode and incubated for $60 \mathrm{~min}$ at $37{ }^{\circ} \mathrm{C}$. To remove nonspecifically bound cells, the sensors were then rinsed thoroughly with PBS and deionized water twice each and blew awhile with a stream of nitrogen.

For all $\mathrm{CV}$ and EIS measurements, $50 \mu \mathrm{L}$ of electrolyte solution applied to the electrochemical reaction area of the GNP-SPCE immunosensor and incubated for $60 \mathrm{~s}$ at room temperature.

Potential of CV experiments was scanned from -1.2 to $1.2 \mathrm{~V}$ with a scan rate of $100 \mathrm{mV} / \mathrm{s}$. All of current and potential data were recorded by the electrochemical station.

All EIS tests were conducted in an open circuit (the open circuit potential is $0.13 \mathrm{~V}$ ). Nyquist diagrams (imaginary impedance $v s$. real impedance) were recorded from $0.1 \mathrm{~Hz}$ to $100 \mathrm{KHz}$ with amplitude of $5 \mathrm{mV}$.

\subsection{Data Analysis}

EIS data were used for simulation of the immunosensor by the ZVIEW software. Seventy-two data points from each measured spectrum were automatically selected by the software for inputting into an equivalent circuit to generate a fitting spectrum. The difference in electron-transfer resistance before and after the bacterial cells binding to the sensor surface was taken as the signal produced by the immune reaction between immobilized antibodies and the cells. Besides, each experiment was repeated three times using three different GNP-SPCEs to test the reproducibility of the immunosensor. All data were expressed with mean signals and \pm standard deviation (S.D.).

\section{Results and Discussion}

\subsection{Electrochemical Characteristics of Brucella Melitensis Immunosensor}

On the GNP-SPCE surface, the GNPs were used to increase the electrode specific surface areas and greatly increase the amount of immobilized biomolecules. The results of Brucella melitensis cells bound to the surface of the GNP-modified SPCE with antibodies immobilized are shown by SEM images (Figure 2). Figure 2a shows the clean surface of the GNP-SPCE before used. Figure 2b,c shows the difference between a solution with low cell concentrations $\left(4 \times 10^{3} \mathrm{CFU} / \mathrm{mL}\right)$ and high cell concentrations $\left(4 \times 10^{7} \mathrm{CFU} / \mathrm{mL}\right)$. It can be seen clearly that the solution with low cell concentrations 
results in few bacteria being immobilized on the sensor surface, while the solution with high cell concentrations results in much more bacteria immobilized on the sensor surface. The Brucella melitensis cells were observed to be ellipsoidal (in the red square frame) that were interacted with antibodies on the GNP-SPCE surface by noncovalent bonds [21].

Figure 2. SEM images of the GNP-SPCE surface. (a) Clean surface; (b) Bacteria bound to surface from sample of $4 \times 10^{3} \mathrm{CFU} / \mathrm{mL}$; (c) Bacteria bound to surface from sample of $4 \times 10^{7} \mathrm{CFU} / \mathrm{mL}$.

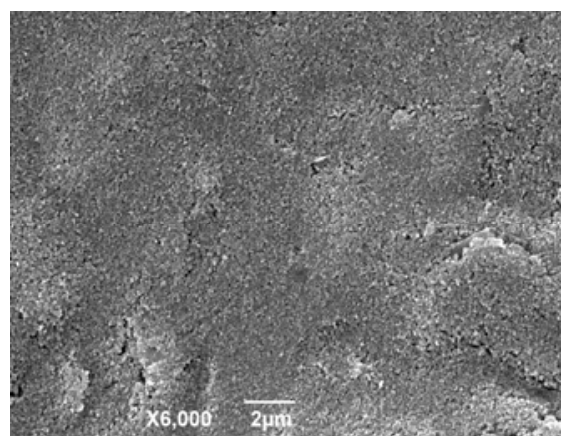

(a)

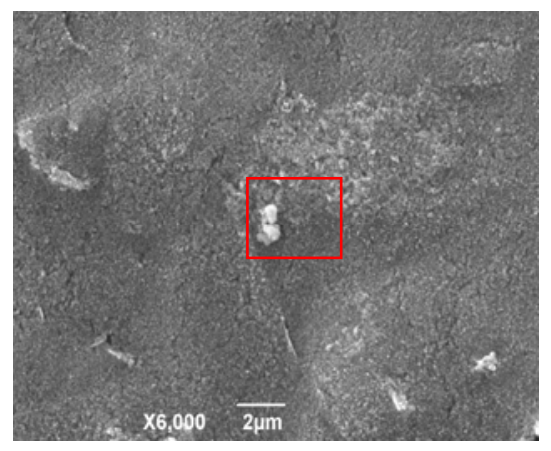

(b)

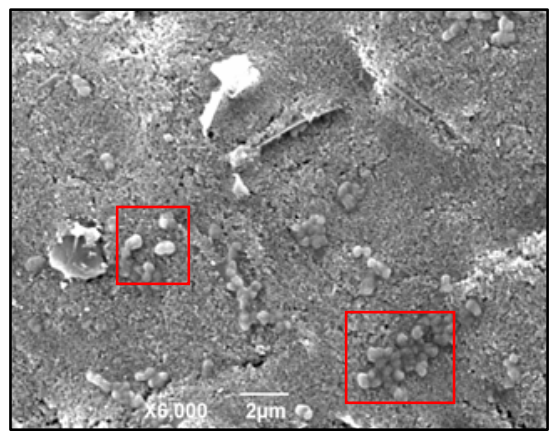

(c)

The adsorption of insulating materials on conductive supports is anticipated to alter the interfacial electron transfer features at the electrode surface [22]. Therefore, impedance experiments were used for confirmation of the stepwise changes of the Brucella melitensis immunosensor. Figure 3 depicts the Nyquist diagrams of GNP-SPCEs obtained under the following conditions: (a) at the bare GNP-SPCE; (b) after antibody immobilization; (c) after blocked with BSA; and (d) after Brucella melitensis cells $\left(4 \times 10^{5} \mathrm{CFU} / \mathrm{mL}\right)$ binding in the presence of $\left[\mathrm{Fe}(\mathrm{CN})_{6}\right]^{3-/ 4-}$ as a redox probe. As shown in Figure 3, each of the impedance spectra includes a semicircle portion and a linear line portion, which corresponds to the electron transfer process and diffusion process respectively. The Nyquist diagrams can be simulated with an equivalent circuit which is given in Scheme I, where $R_{\mathrm{S}}$ is the resistance of the electrolyte solution, $C P E$ is the constant phase element, $R_{\mathrm{ct}}$ is the electron-transfer resistance, and $W$ is the Warburg element [23]. The impedance of $C P E$ and $W$ are given by the flowing equations [24]:

$$
\begin{gathered}
Z_{C P E}=\frac{1}{Q \times(\mathrm{j} \omega)^{\alpha}} \\
Z_{W}=R \times \operatorname{ctnh}\left[(j T \omega)^{P}\right] /(j T \omega)^{P}
\end{gathered}
$$

where $Q$ and $\alpha$ are the characters of constant phase element. $R, T$, and $P$ are the characteristic values of Warburg element. $R$ is a resistance. $T$ is equal to $\mathrm{L}^{2} / \mathrm{D}$ ( $\mathrm{L}$ is the effective diffusion thickness, and $\mathrm{D}$ is the effective diffusion coefficient). $P$ is an exponent. $\omega$ is the frequence of excitation sources and $j$ is the imaginary unit. To use Equation (2), we set $P=0.5$. 
Figure 3. Nyquist diagrams and the corresponding simulated results (solid line) of GNP-SPCEs obtained under the following conditions: (a) at the bare GNP-SPCE; (b) after antibody immobilization; (c) after blocked with BSA; and (d) after Brucella melitensis cells $\left(4 \times 10^{5} \mathrm{CFU} / \mathrm{mL}\right)$ binding in the frequency range from $0.1 \mathrm{~Hz}$ to $100 \mathrm{kHz}$. A sinusoidal potential modulation of $\pm 5 \mathrm{mV}$ amplitude was superimposed on the open circuit potential $(0.13 \mathrm{~V})$. Electrolyte: $2.5 \mathrm{mM} \mathrm{K}\left[\mathrm{Fe}(\mathrm{CN})_{6}\right]+2.5 \mathrm{mM} \mathrm{K}_{3}\left[\mathrm{Fe}(\mathrm{CN})_{6}\right]+0.1 \mathrm{M}$ $\mathrm{KCl}+10 \mathrm{mM}$ PBS $(\mathrm{pH}=7.4)$.

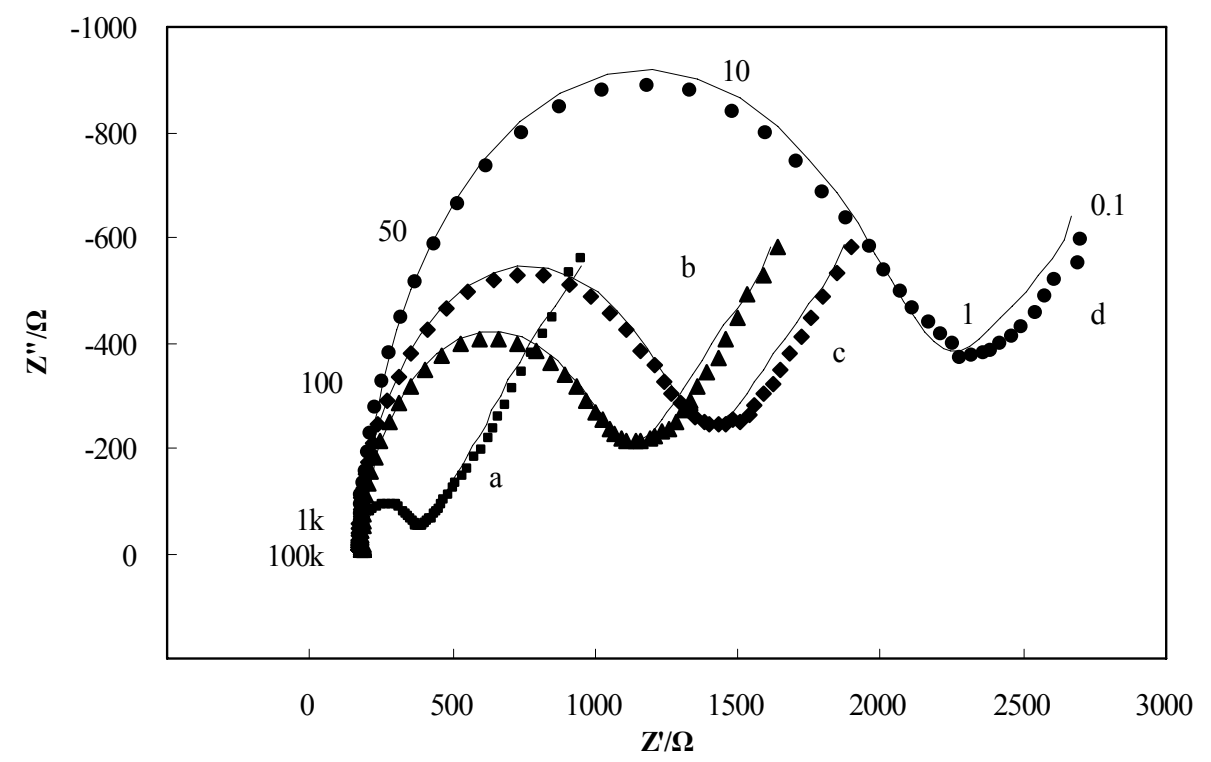

Scheme I. Equivalent circuit for Nyquist plots. $R_{\mathrm{S}}$, solution resistance; $C P E$, constant phase element; $R_{\mathrm{ct}}$, electron-transfer resistance; $W$, Warburg element due to diffusion of the redox couple $\left(\left[\mathrm{Fe}(\mathrm{CN})_{6}\right]^{4-} /\left[\mathrm{Fe}(\mathrm{CN})_{6}\right]^{3-}\right)$ to the interface from the bulk of the electrolyte.

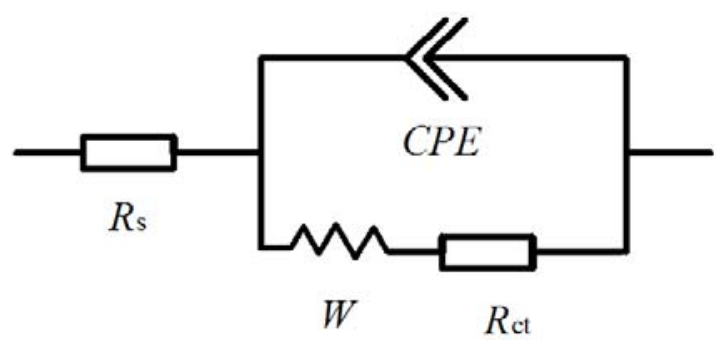

By fitting the electrochemical impedance spectra to the equivalent circuit, the simulated results are shown in Figure 3 (solid line) and the values of all electrical elements in the equivalent circuit are listed in Table 1. According to the Table 1, the electron-transfer resistance of a GNP-modified SPCE (Figure 3, curve a) is $204.6 \Omega$, which is very small compared with the values of $R_{\mathrm{ct}}$ for the other cases. It agrees with the fact that the electron transfer process on the GNP-modified SPCE surface is very fast, which is almost a diffusional limited electron transfer process. The immobilization of antibodies on the electrode surface occurred through direct physical adsorption of the molecules. Assembly of antibody on the GNP-SPCE surface (Figure 3, curve b) generated almost no change in $R_{\mathrm{S}}$ and the Warburg element values, but significant change in $R_{\mathrm{ct}}$ due to the immobilized insulating protein layer on the electrode surface introduced an electron-transfer barrier. The increased electron-transfer resistance in 
Nyquist plots after BSA blocking (Figure 3, curve c) was because BSA has blocked the free sites on the sensor surface, leaving only the available recognition sites for antigen binding. Similarly, after the treatment of the antigen-antibody interaction was made (Figure 3, curve d), the increment of $R_{\mathrm{ct}}$ became the most significant among all the elements in the table and the increment rate increased quite markedly. From these results, it can be summarized that electrochemical impedance spectroscopy is capable of monitoring the change in electron transfer resistance resulting from the immobilization of antibodies and the binding of Brucella melitensis cells.

Table 1. Simulated values of all elements in the equivalent circuit and percentage of their changes ${ }^{\mathrm{a}}$.

\begin{tabular}{|c|c|c|c|c|c|c|}
\hline \multirow[b]{2}{*}{ Circuit Elements } & \multirow{2}{*}{$\begin{array}{c}\boldsymbol{R}_{\mathbf{S}} \\
{[\Omega]}\end{array}$} & \multicolumn{2}{|c|}{$C P E$} & \multirow[b]{2}{*}{$\begin{array}{l}R_{\mathrm{ct}} \\
{[\Omega]}\end{array}$} & \multicolumn{2}{|c|}{$\boldsymbol{W}$} \\
\hline & & $\begin{array}{c}Q \\
{\left[\mu \mathrm{F} \cdot \mathbf{s}^{-(1-\alpha)}\right]}\end{array}$ & $\alpha$ & & $\begin{array}{l}W_{\mathbf{R}} \\
{[\Omega]}\end{array}$ & $\begin{array}{l}W_{\mathrm{T}} \\
{[\mathbf{s}]}\end{array}$ \\
\hline GNP-modified SPCE & $167.60 \pm 0.78$ & $2.72 \pm 0.25$ & $0.92 \pm 0.01$ & $204.60 \pm 2.25$ & $2224 \pm 174.91$ & $9.79 \pm 1.62$ \\
\hline After antibody immobilization & $175.90 \pm 0.60$ & $5.13 \pm 0.18$ & $0.97 \pm 0.00$ & $849.60 \pm 6.02$ & $2080 \pm 169.49$ & $7.52 \pm 1.37$ \\
\hline Increment rate & $4.95 \%$ & $88.40 \%$ & $5.25 \%$ & $315.25 \%$ & $-6.47 \%$ & $-23.19 \%$ \\
\hline After antibody immobilization & $175.90 \pm 0.60$ & $5.13 \pm 0.18$ & $0.97 \pm 0.00$ & $849.60 \pm 6.02$ & $2080 \pm 169.49$ & $7.52 \pm 1.37$ \\
\hline After BSA blocking & $172.70 \pm 0.58$ & $5.32 \pm 0.14$ & $0.96 \pm 0.00$ & $1111 \pm 7.25$ & $2097 \pm 195.05$ & $7.49 \pm 1.57$ \\
\hline Increment rate & $-1.82 \%$ & $3.62 \%$ & $-0.15 \%$ & $30.77 \%$ & $0.82 \%$ & $-0.37 \%$ \\
\hline After BSA blocking & $172.70 \pm 0.58$ & $5.32 \pm 0.14$ & $0.96 \pm 0.00$ & $1111 \pm 7.25$ & $2097 \pm 195.05$ & $7.49 \pm 1.57$ \\
\hline $\begin{array}{c}\text { After Brucella melitensis } \\
\text { binding }\end{array}$ & $175.40 \pm 0.61$ & $6.28 \pm 0.13$ & $0.96 \pm 0.00$ & $1788 \pm 12.98$ & $2124 \pm 246.22$ & $6.74 \pm 1.77$ \\
\hline Increment rate & $1.56 \%$ & $18.09 \%$ & $-0.57 \%$ & $60.94 \%$ & $1.29 \%$ & $-10.01 \%$ \\
\hline
\end{tabular}

${ }^{a}$ Numbers of data for simulation, $72 ;$ Brucella melitensis, $4 \times 10^{5} \mathrm{CFU} / \mathrm{mL}$.

CV experiments were used to further confirm the surface changes for the attachment of antibodies and antigens on the immunosensor. Theoretically, the changes in peak current and the separation of peak potentials in voltammograms at different electrode surfaces are related to the electron-transfer rate constant, and thus, the electron-transfer resistance [25]. Figure 4 shows the cyclic voltammograms of the GNP-SPCEs obtained under the following conditions: (a) at the bare GNP-modified SPCE; (b) after antibody immobilization; (c) after BSA blocking; and (d) after cell binding $\left(4 \times 10^{5} \mathrm{CFU} / \mathrm{mL}\right.$ ) in PBS solution containing $2.5 \mathrm{mM}\left[\mathrm{Fe}(\mathrm{CN})_{6}\right]^{3-/ 4-}(1: 1$ mole ratio) and $0.1 \mathrm{M} \mathrm{KCl}$. When the electrode was immobilized with antibodies, a decrease in peak current (from 100.1 to $77.4 \mu \mathrm{A}$ ) and an increase in the separation of peak potentials (from 142 to $170 \mathrm{mV}$ ) were observed. After the electrode was blocked with BSA, the electron-transfer of the electrode was measured to decrease further from 77.4 to $74.1 \mu \mathrm{A}$. Especially, a decrease of $20.2 \%$ in peak current (from 74.1 to $59.1 \mu \mathrm{A}$ ) was clearly observed after the antigen-antibody interaction. The cell binding also resulted in an increase of $22.2 \%$ in the separation of peak potentials (from 180 to $220 \mathrm{mV}$ ). The increase in the separation of the peak potentials and decrease in peak current after the different electrode processing indicate that the immobilization of antibody and the binding of cells perturb the electron transfer rate, which are in good agreement with the increase in the electron transfer resistance observed in the impedance spectra. 
Figure 4. Cyclic voltammograms of the GNP-SPCEs obtained under the following conditions: (a) at the bare GNP-modified SPCE; (b) after antibody immobilization; (c) after BSA blocking; and (d) after cell binding $\left(4 \times 10^{5} \mathrm{CFU} / \mathrm{mL}\right)$ in the solution of $2.5 \mathrm{mM} \mathrm{K}_{4}\left[\mathrm{Fe}(\mathrm{CN})_{6}\right]+2.5 \mathrm{mM} \mathrm{K}_{3}\left[\mathrm{Fe}(\mathrm{CN})_{6}\right]+0.1 \mathrm{M} \mathrm{KCl}+10 \mathrm{mM} \mathrm{PBS}(\mathrm{pH}=7.4)$. Scan rate, $100 \mathrm{mV} / \mathrm{s}$. The reduction peak: $\mathrm{R}_{1}$. The oxidation peak: $\mathrm{O}_{1}$.

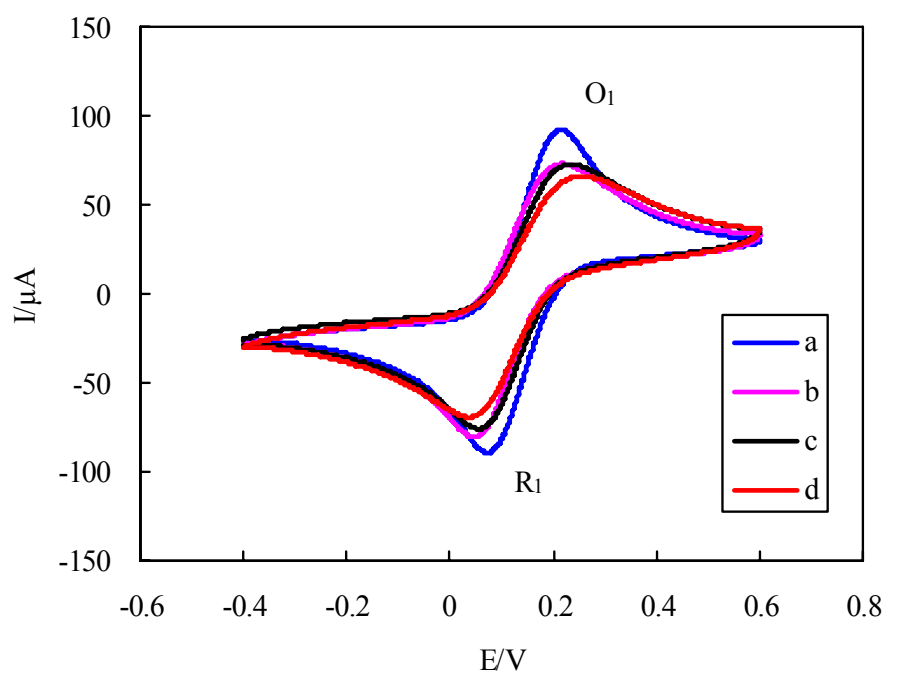

\subsection{Detection Limits and Specificity of Brucella Melitensis Immunosensor}

Brucella melitensis concentrations, from $4 \times 10^{3}$ to $4 \times 10^{8} \mathrm{CFU} / \mathrm{mL}$ were prepared by serial dilution in PBS buffer. A volume of $15 \mu \mathrm{L}$ sample of each bacterial suspension was taken for immunosensing to evaluate the detection range by calculation of the electron-transfer resistance change before and after cells binding $\left(\Delta R_{\mathrm{ct}}\right)$. Figure 5 shows the derived calibration plot that corresponds to the electron-transfer resistance changes at the sensing interface with different concentrations of cell. A linear relationship between the value of $\Delta R_{\mathrm{ct}}$ and logarithmic value of the cell concentration was found from $4 \times 10^{4}$ to $4 \times 10^{6} \mathrm{CFU} / \mathrm{mL}$. The detection limit of the immunosensor was approximately $1 \times 10^{4} \mathrm{CFU} / \mathrm{mL}$ in PBS(the limit of detection was calculated as the concentration yielding a signal equal to three times the standard deviation of the blank (intercept) divided by the slope). The total test process, including binding, washing, and sensing, took about $1.5 \mathrm{~h}$ for each test.

The cross-reactivity for antibodies is an important concern in immunoassy. To assess the specificity of the GNP-SPCE immunosenor for Brucella melitensis, interference study was conducted with Escherichia coli O157:H7 and Staphylococcus aureus at a concentration around $4 \times 10^{6} \mathrm{CFU} / \mathrm{mL}$ as depicted in Figure 6. It can be seen that the value of $\Delta R_{\mathrm{ct}}$ for Brucella melitensis is significantly higher than the values obtained in blank. While the values of $\Delta R_{\mathrm{ct}}$ for the bacteria other than Brucella melitensis are similar to blank. Thereby the cross-reactivity of the Brucella melitensis antibodies to Escherichia coli O157:H7 and Staphylococcus aureus is negligible. The results indicate that the immuosensor has good specificity for Brucella melitensis detection. 
Figure 5. The $\Delta R_{\mathrm{ct}}$ due to the different concentrations of Brucella melitensis cells detected by the GNP-SPCE immunosensor. $\Delta R_{\mathrm{ct}}$ was calculated by $R_{\mathrm{ct}(\mathrm{Ab}-\mathrm{Ag})}-R_{\mathrm{ct}(\mathrm{Ab}) \text {, where }}$ $R_{\mathrm{ct}(\mathrm{Ab}-\mathrm{Ag})}$ is the value of the electron transfer resistance after antigen binding to antibody, $R_{\mathrm{ct}(\mathrm{Ab})}$ is the value of the electron transfer resistance after BSA blocking. Each value of $R_{\mathrm{ct}}$ was derived from three independent measurements.

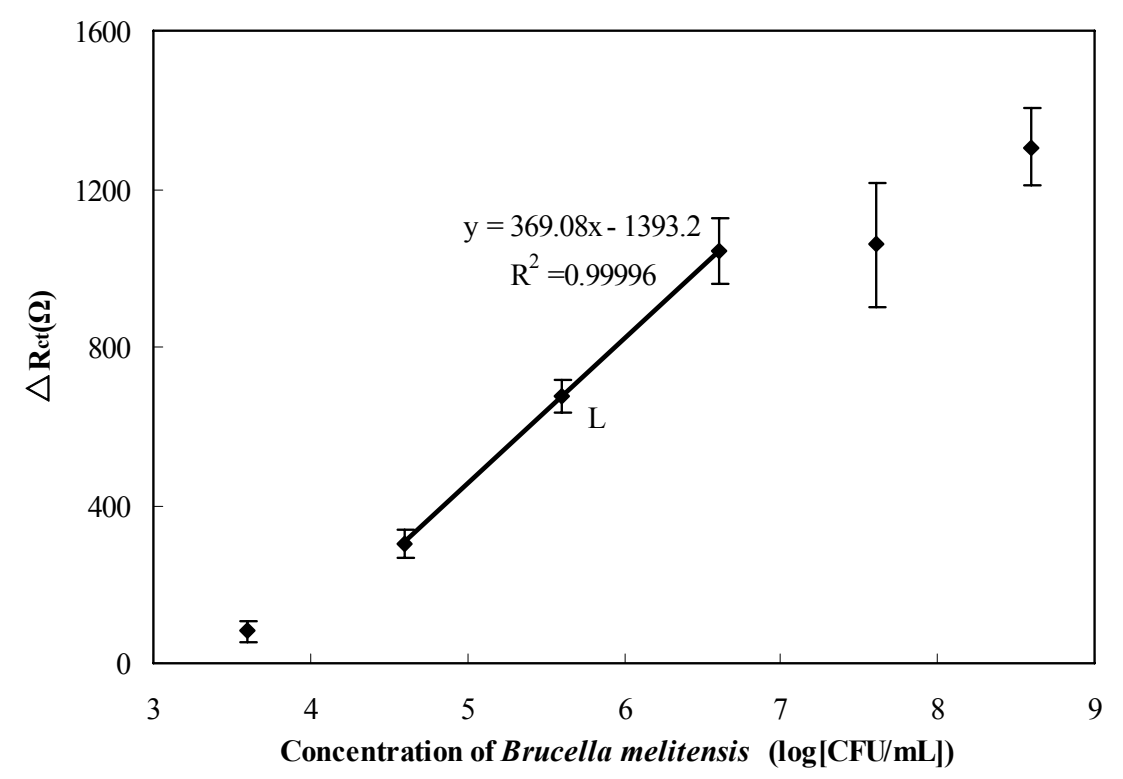

Figure 6. Specificity of the GNP-SPCE immunosenor for Brucella melitensis.

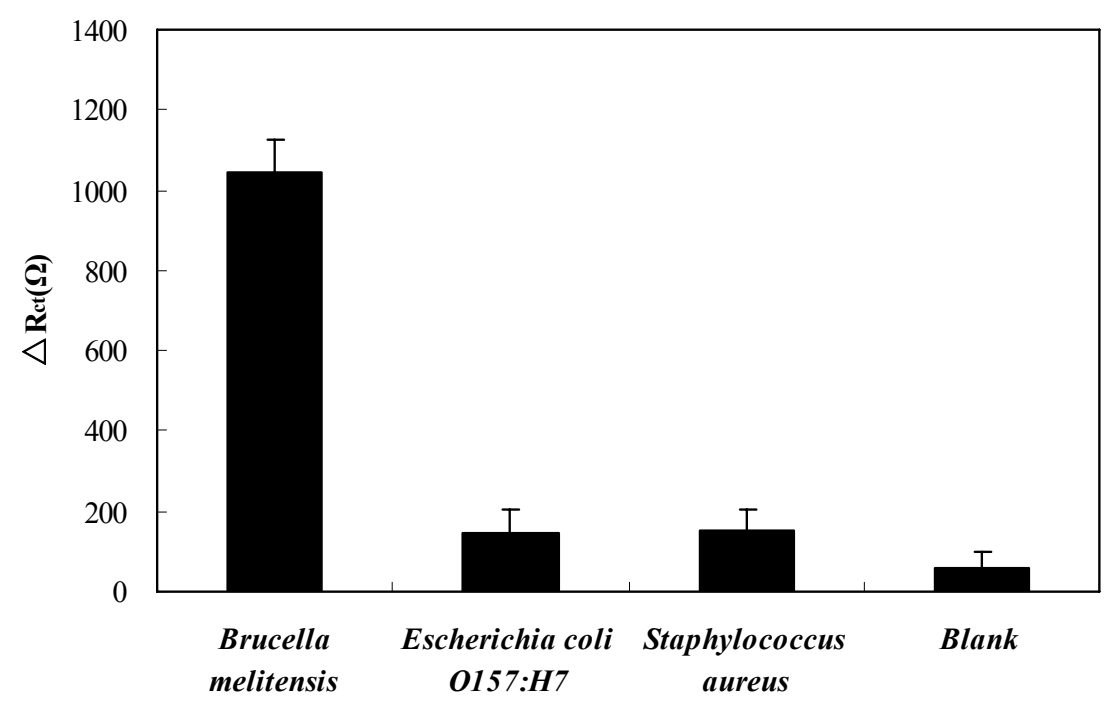

\subsection{Detection of Brucella Melitensis in Real-Life Samples}

Brucellosis, especially that arising from Brucella melitensis, is often foodborne, and unpasteurized milk and dairy products are common vehicles of transmission. In order to test the sensitivity of the immunosensor, different concentrations of Brucella melitensis cells were spiked with milk to simulate the real-life milk sample. A volume of $15 \mu \mathrm{L}$ sample of each bacterial suspension was evaluated with this developed immunosensor and the analysis results are reported in Figure 7. Statistical significance of mean differences between concentrations was evaluated by a one-way ANOVA and t test to a 
significance of $95 \%(\mathrm{p}<0.05)$. The statistical analysis shows that the lower detection limit was $4 \times 10^{5} \mathrm{CFU} / \mathrm{mL}$. These results reveal that this immunosensor is capable of Brucella melitensis detection present in milk. But how to use this technique in reality still need to be studied further.

Figure 7. Detection of Brucella melitensis in milk samples. The mean of each $\Delta R_{\mathrm{ct}}$ was calculated from three independent measurements of GNP-SPCE immunosensors.

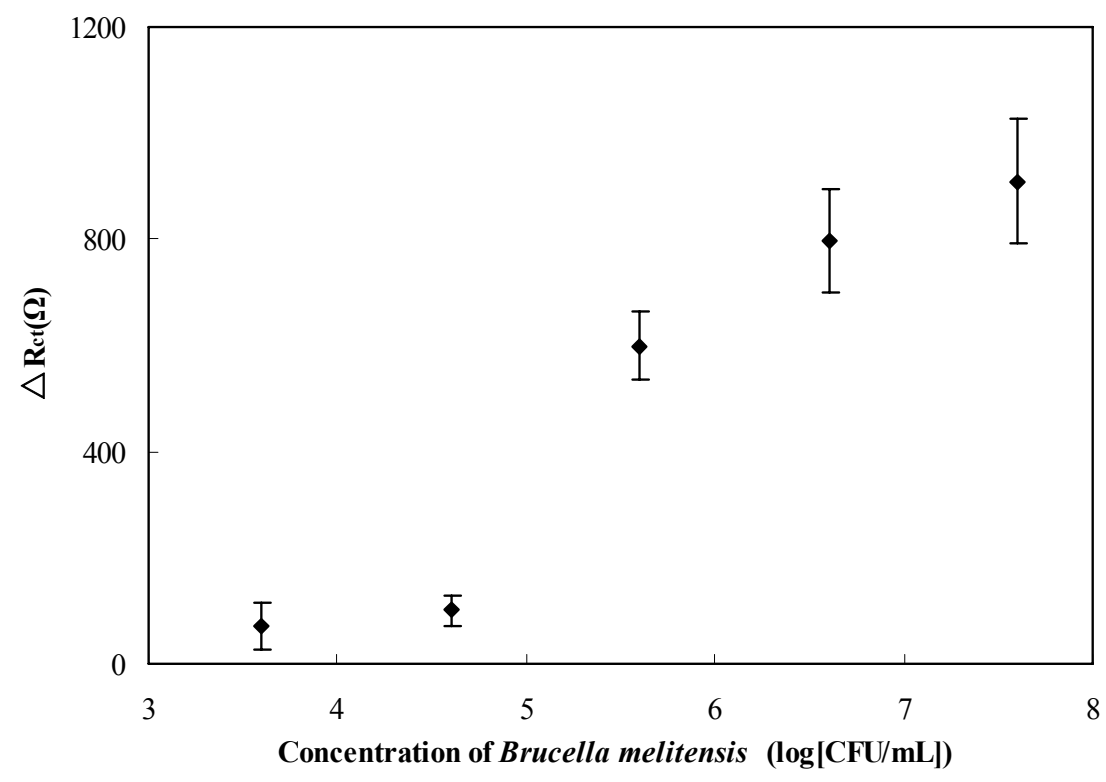

\section{Conclusions}

A label-free impedance immunosensor for Brucella melitensis detection was developed based on GNP-SPCE. The disposable GNP-SPCE was used for sensing by electrochemical impedance spectroscopy (EIS) in the presence of $\left.\left[\mathrm{Fe}(\mathrm{CN})_{6}\right]^{3-/ 4-}\right]$. A general electronic equivalent model was introduced for modeling the performance of the immunosensor. Among these impedance components, the greatest change was found in electron-transfer resistance due to the cell binding. The label-free impedance biosensor showed linearity from $4 \times 10^{4}$ to $4 \times 10^{6} \mathrm{CFU} / \mathrm{mL}$ with a detection limit of $1 \times 10^{4} \mathrm{CFU} / \mathrm{mL}$ in pure culture. When testing real-life samples, the biosensor was able to detect as low as $4 \times 10^{5} \mathrm{CFU} / \mathrm{mL}$ of Brucella melitensis in milk samples in less than $1.5 \mathrm{~h}$. Interference from other bacteria was eliminated by the use of specific antibodies. This biosensing method uses a low-cost disposable electrode. It is hand-held operation, and no complex pretreatment is needed, thus would allow in the future the development of easy-to-use and portable devices for the rapid monitoring of Brucella melitensis.

\section{Acknowledgments}

This research was funded by the National Natural Science Foundation of China through grant number 30871445, the Shanxi Scholarship Council of China through grant number 2013-061 and the Innovative Project for Excellent Postgraduate in Shanxi of China through grant number 20123049. 


\section{Conflict of Interest}

The authors declare no conflict of interest.

\section{References}

1. Deqiu, S.; Donglou, X.; Jiming, Y. Epidemiology and control of brucellosis in China. Vet. Microbiol. 2002, 90, 165-182.

2. Zhang, W.Y.; Guo, W.D.; Sun, S.H; Jiang, J.F.; Sun, H.L.; Li, S.L.; Liu, W.; Cao, W.C. Human brucellosis, Inner Mongolia, China. Emerg. Infect. Dis. 2010, 16, 2001-2003.

3. Poester, F.P.; Nielsen, K.; Samartino, L.E.; Yu, W.L. Diagnosis of brucellosis. Open Vet. Sci. J. 2010, 4, 46-60.

4. Corbel, M.J. Clinical Manifestation. Brucellosis in Humans and Animals, 1st ed.; World Health Organization: Geneva, Switzerland, 2006; pp. 87-89.

5. Liebes, Y.; Marks, R.S.; Banai, M. Chemiluminescent optical fiber immunosensor detection of Brucella cells presenting smooth-A antigen. Sens. Actuators B Chem. 2009, 140, 568-576.

6. O’Leary, S.; Sheahan, M.; Sweeney, T. Brucella abortus detection by PCR assay in blood, milk and lymph tissue of serologically positive cows. Res. Vet. Sci. 2006, 81, 170-176.

7. Mitka, S.; Anetakis, C.; Souliou, E.; Diza, E.; Kansouzidou, A. Evaluation of different PCR assays for early detection of acute and relapsing brucellosis in humans in comparison with conventional methods. J. Clin. Microbiol. 2007, 45, 1211-1218.

8. Li, Z.Z.; Gong, F.C.; Shen, G.L.; Yu, R.Q. Bacteria-modified amperometric immunosensor for a Brucella melitensis antibody assay. Anal. Sci. 2002, 18, 625-630.

9. Gong, F.C.; He, D.S.; Cao, Z.; Tan, S.Z.; Tan, Y.F. An amperometric enzyme-linked immunosensor using resveratrol as the substrates for horseradish peroxidase for Brucella Melitensis antibody assay. Chin. J. Anal. Chem. 2007, 35, 1783-1786.

10. Varshney, M.; Li, Y.B.; Srinivasan, B.; Tung, S. A label-free, microfluidics and interdigitated array microelectrode-based impedance biosensor in combination with nanoparticles immunoseparation for detection of Escherichia coli O157:H7 in food samples. Sens. Actuators B Chem. 2007, 128, 99-107.

11. Gupta, G.; Kumar, A.; Boopathi, M.; Thavaselvam,D.; Singh, B.; Vijayaraghavan, R. Rapid and quantitative determination of biological warfare agent Brucella Abortus CSP-31 using Surface Plasmon Resonance. Anal. Bioanal. Electrochem. 2011, 3, 26-37.

12. Patris, S.; Vriese, C.D.; Prohoroff, F.; Calvo, E.B.; Martínez J.A.; Kauffmann, J.M. Anti-clostridium tetani antibody determination in serum samples by amperometric immunosensing. Electroanal. 2010, 22, 41-48.

13. Kuralay, F.; Campuzano, S.; Haake, D.A.; Wang, J. Highly sensitive disposable nucleic acid biosensors for direct bioelectronic detection in raw biological samples. Talanta 2011, 85, 1330-1337.

14. Lin, Y.H.; Chen, S.H.; Chuang, Y.C.; Lu, Y.C.; Shen, T.Y.; Chang, C.A.; Lin, C.S. Disposable amperometric immunosensing strips fabricated by $\mathrm{Au}$ nanoparticles-modified screen-printed carbon electrodes for the detection of foodborne pathogen Escherichia coli O157:H7. Biosens. Bioelectron. 2008, 23, 1832-1837. 
15. Labib, M.; Martić, S.; Shipman, P.O.; Kraatz, H.B. Electrochemical analysis of HIV-1 reverse transcriptase serum level: Exploiting protein binding to a functionalized nanostructured surface. Talanta 2011, 85, 770-778.

16. Escamilla-Gómez, V.; Hernández-Santos, D.; González-García, M.B.; Pingarrón-Carrazón, J.M.; Costa-García, A. Simultaneous detection of free and total prostate specific antigen on a screen-printed electrochemical dual sensor. Biosens. Bioelectron. 2009, 24, 2678-2683.

17. Radke, S.M.; Alocilja, E.C. A high density microelectrode array biosensor for detection of E. coli O157. Biosens. Bioelectron. 2005, 20, 1662-1667.

18. Zuo, Y.M.; Chakrabartty, S.; Muhammad-Tahir, Z.; Pal, S.; Alocilja, E.C. Spatio-temporal processing for multichannel biosensors using support vector machines. IEEE Sens. J. 2006, 6, $1644-1651$.

19. Viswanathan, S.; Rani, C.; Ho, J.A. Electrochemical immunosensor for multiplexed detection of food-borne pathogens using nanocrystal bioconjugates and MWCNT screen-printed electrode. Talanta 2012, 94, 315-319.

20. Laczka, O.; Baldrich, E.; Muñoz, F.X.; del Campo, F.J. Detection of Escherichia coli and Salmonella typhimurium using interdigitated microelectrode capacitive immunosensors: The importance of transducer geometry. Anal. Chem. 2008, 80, 7239-7247.

21. Cho, E.C.; Choi, J.W.; Lee, M.; Koo, K.K. Fabrication of an electrochemical immunosensor with self-assembled peptide nanotubes. Colloid Surf. A-Physicochem. Eng. Asp. 2008, 313-314, 95-99.

22. Wang, M.J.; Wang, L.Y.; Wang, G.; Ji, X.H.; Bai, Y.B.; Li, T.J.; Gong, S.Y.; Li, J.H. Application of impedance spectroscopy for monitoring colloid Au-enhanced antibody immobilization and antibody-antigen reactions. Biosens. Bioelectron. 2004, 19, 575-582.

23. Katz, E.; Willner, I. Probing biomolecular interactions at conductive and semiconductive surfaces by impedance spectroscopy: Routes to impedimetric immunosensors, DNA-sensors, and enzyme biosensors. J. Electroanal. 2003, 15, 913-947.

24. Tan, F.; Leung, P.H.M.; Liu, Z.B.; Zhang, Y.; Xiao, L.; Ye, W.W.; Zhang, X.; Yi, L.; Yang, M. A PDMS microfluidic impedance immunosensor for E. coli O157:H7 and Staphylococcus aureus detection via antibody-immobilized nanoporous membrane. Sens. Actuators B Chem. 2011, 159, 328-335.

25. Yang, L.J.; Li, Y.B.; Erf, G.F. Interdigitated array microelectrode-based electrochemical impedance immunosensor for detection of Escherichia coli O157:H7. Anal. Chem. 2004, 76, 1107-1113.

(C) 2013 by the authors; licensee MDPI, Basel, Switzerland. This article is an open access article distributed under the terms and conditions of the Creative Commons Attribution license (http://creativecommons.org/licenses/by/3.0/). 